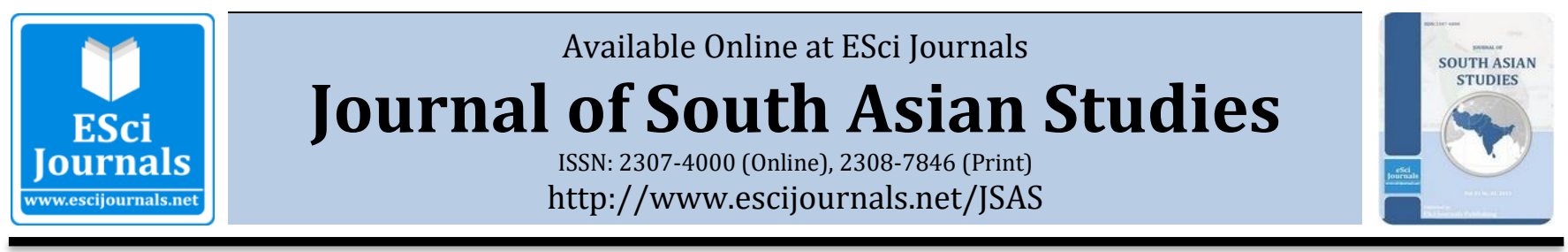

\title{
STRUCTURAL CHANGE IN THE BANGLADESH ECONOMY AN ANALYSIS OF COMPOSITION OF OUTPUT
}

\author{
Tonmoyee H. Ayon* \\ Department of Economics, University of Chittagong, Chittagong, Bangladesh.
}

\section{A B S T R A C T}

This paper examines the changes in the sectoral composition of Bangladesh's GDP over the period $1973-2017$ both at the aggregated and disaggregated levels. As expected, perceptible changes occurred at the aggregated level with the share of the agricultural sector declining steadily while the relative shares of industry and services showing increasing trends. All three broad sectors of the Bangladesh economy grew over time. It appears from the study that the industrial sector grew the fastest followed by the services sector. The share of agriculture fell from about 39 percent in 1973 to 16 percent in 2017. During the same period, the share of the industrial sector rose from just over 15 percent to more than 31 percent. On the other hand, the share of the services sector increased from 46 percent in 1973 to about 54 percent in 2016. An analysis of the intra-sectoral composition suggests that the production of some commodities grew faster than others, and then over time some new commodities gained prominence thereby causing remarkable structural changes.

Keywords: Bangladesh economy, Composition, GDP, Growth Rate, Share, Sectoral, Structural Change.

\section{INTRODUCTION}

Bangladesh faced alarming development odds at the time of independence in 1971. The Bangladesh economy was aptly characterized by high population growth, low resource-base, persistent food shortages, high dependency on foreign aid and imports, limited production of exportable, persistent socio-political instability, notable income inequality, multidimensional poverty, and low levels of human development. Recurrent natural disasters and dislocations caused by the war of liberation only added to the agony of the economy. Thus, economic growth and development of the country looked rather dreary.

However, the economy of Bangladesh has performed considerably well over the past two decades, especially in recent years. A reasonably steady annual rate of growth of over 4 percent has been achieved by the economy during the first two decades of her independence against the benchmark trend GDP growth rate of 3.2 percent during 1950-1970 and was successful in moving into the

\footnotetext{
* Corresponding Author:

Email ID: tonmoyee1978@gmail.com

(C) 2018 ESci Journals Publishing. All rights reserved.
}

higher growth trajectory of nearly 5 percent during the 1990s. The economy achieved a trend growth rate of 5.8 percent during 2000-2011 and 6.53 percent for last couple of years. The acceleration in the pace of growth started in the early 1990s when Bangladesh returned to a democratic form of government after almost a decade of autocratic rule. Furthermore, the wide-ranging policy reforms involving deregulation of investment, liberalization of trade as well as the regulated exchange rate regime, financial and fiscal sector reforms and contemporary monetary policy also contributed to the growth.

The economy of Bangladesh is a rapidly developing market-oriented economy which is the $44^{\text {th }}$ largest in the world in nominal terms, and $32^{\text {nd }}$ largest by purchasing power parity. IMF ranked the economy as the $2^{\text {nd }}$ fastest growing major economy with a rate of 7.28 percent and it is among the Next Eleven or N-11 of Goldman Sachs and D-8 economies, with a gross domestic product of $\$ 751$ billion in PPP terms and $\$ 273$ billion in nominal terms in 2018. The economy has grown at the rate of 6-7 percent per annum over a couple of years and it is remarkable that about half of the GDP is being derived from the services 
sector. Although, agriculture still accounts for $40 \%$ of total employment. The relative contribution of the manufacturing sector is on the rise particularly the credit goes to the RMG sector.

In the world perspective, at present, Bangladesh is considered as a noteworthy example of gaining progress in different socio-economic indicators despite daunting challenges. Therefore, the World Bank Group's new Country Partnership Framework (CPF) 2016-2020 has decided to support Bangladesh to achieve its vision of reaching middle-income status by its $50^{\text {th }}$ birthday in 2021. However, the country is at an important juncture, with the right policies and timely action it can move up within the middle-income bracket whereas for that Bangladesh need to focus on accelerating its growth, need to foster social inclusion as well as to strengthen climate and environmental management vis-á-vis the country has to remove the barriers to higher growth posed by low access to reliable and affordable power, less developed infrastructure, rapid urbanization and vulnerability to climate change and natural disasters as well. Amidst of this, a remarkable change has occurred in the composition of output in the economy as a share of agriculture to GDP has declined considerably, contrarily, the share of industry, as well as services sector, is on escalation.

\section{STUDY BACKGROUND}

The literature concerning the macroeconomic performance of Bangladesh and the structural changes that may have occurred is just evolving. Nahar (2006) argues that the GDP of Bangladesh indicates, the economy was backward for prolonging. Moreover, in the years after independence, the size of real GDP, per capita GDP, and their growth rates were small. Although the condition improved since 1990 but the growth trend and the structural changes of GDP is not satisfactory due to the shortage of domestic food production, narrow structure of exports, high dependency on imports, failure in the invocation of much needed foreign direct investment (FDI), persistent losses in the public enterprises, poor infrastructure, inefficient taxation system, political instability and so on. She further argues that agricultural as well as industrial GDP are low in recent years as compared to the swelling GDP of service sectors. To overcome the imbalances, the paper prescribed, modernization in agriculture, proper distribution of subsidies and interest-free loans among the peasants, balanced growth rates of large scale industries, small and cottage industries, and enhanced domestic investments are necessary.

According to Mujeri (2004) growth performance of Bangladesh economy has not been spectacular over the past two decades although there has been a moderate acceleration in growth during 1997-2007 compared with the early periods, and the acceleration is accompanied with a significant change in the composition of output. It depicts that the relative share of agriculture in GDP has declined over time; on the other hand, the share of industry correspondingly increased with greater participation of the private sector accompanied with an impressive performance of manufacturing industry and construction activities and share of the services sector remained almost unaffected.

Diego Marin Benitez (2012) in his study, demonstrated that, the economy of Bangladesh has undergone a notable towards economic and social development, whereas some factors that contributed significantly to this growth, including others are the impressive performance of women, intervention of government and nongovernment organization as well as a deep social change provided by the government civil society. He also argued that the economy has already established the basic conditions for sustained growth and it stays in the "Take - off" stage in accordance with the Rostow's Stages of Economic Growth.

Akanda (2010) observes that the Bangladesh economy has made a gradual higher growth performance over the years including the contribution of the three broad sectors - agriculture, industry and service. However, the variations in growth performances have resulted in a structural transformation among agriculture, industry and service sectors as the composition of GDP has been changed from a descending pattern of 'agriculture, service and industry' to 'service, industry and agriculture'.

Ahmed, Bakht and Yunus (2010) observe that during the first two decades of her independence Bangladesh economy remained predominantly agrarian. During the observed period, the economy experienced a moderate decline in the share of agriculture that was made up by growth in the services sector, particularly transport and communication, community social and personal services. Moreover this declining trend was accelerated during the 1990s, that coincided with the intensified phase of policy reforms that contributed significantly to the rising share of industry to GDP of Bangladesh, (the sub-sector that 
played the vital role are manufacturing, utility, construction and mining) On the contrary, the share of services sector remaining virtually unchanged. Thus, in terms of the composition of GDP, the structural transformation of Bangladesh economy since the early 1990 s seems like a transition from agriculture to industry rather than to serve.

However, as we will show in the subsequent sections, the role of the services sector has been more visible than the industrial sector since 2000 .

All of the above studies and similar ones recognize the gradual occurrence of the structural change in Bangladesh economy, the present study takes up a more elaborate analysis in terms of sample period, the structural changes within the three broad sectors, the interrelationships between the growth of the three subsectors, the probable causes of the structural changes, and the implications for the Bangladesh economy as well.

\section{METHODOLOGY}

As we all know that, research can be defined as a scientific and a systematic search for pertinent information on a particular topic as well as an art of scientific investigation, so we can address research methodology as a way to solve the research problem systematically. The study originated from a need to analyze the research question that is the overall change in the composition of output, their underlying reasons as well as the plausible implication on Bangladesh economy.

This part of the study specifies the method of research used, data collection and instrument used validation and administration of the instrument, including methods implemented to maintain validity and reliability of the instrument, statistical treatment as well as the analysis of the gathered data. A quantitative research approach was followed to conduct the study as it is based on data analysis to generate reliability.

Based on the objectives of the study, it is imperative that we have to rely on secondary data, as the research objectives indicates we need to analyze the Macro Economic issues as for example, GDP per capita, growth rate of GDP, share and as well as growth rate of different sectors and their corresponding sub-sectors, that are generally collected from the secondary sources as well.

However, the most fundamental aspects of selecting the data collection method is based on two factors, that is the scope and its depth. Considering the facts as well, and also to ensure reliability, suitability and adequacy of data, we have followed the most widely used and exercised various publications of the government as well as international bodies and their subsidiary organizations like BBS, ER, WDI, LFS etc. It is mentionable that although we emphasized more on most widely used and reliable sources for data collection purpose but, in course of time as there occurred gradual transformation in the sectoral composition and its contribution has been changed over time, new sectors get prominence whereas few older one gradually lost their importance in some cases available as well as elaborate data on some sectors was not existing. A set of research associate has collected the data from the above mentioned sources and then transferred and organized all potential data of interest to a new Microsoft Excel file.

It is worth mentioning as per objectives of the study to explore the overtime change in the output combination of Bangladesh economy. We laid emphasis on the time period from post-liberation period to till to date.

A simple statistical routine such as, tabular and as well as graphical method were applied to analyze the data collection and to perceive the plausible answers to the research question. The detailed analysis of research data from the initial and main study were presented in the subsequent sections.

\section{OBJECTIVES OF THE STUDY}

Perceptible changes have occurred in the structural composition of output in the Bangladesh economy. Empirical literature to date has addressed these issues only sporadically. No systematic study has yet been undertaken from any side. The present study is an attempt to an in-depth analysis of the trends in the sectoral composition of Bangladesh's GDP and the causes of the changes therein. Our present study focuses on the following specific objectives:

a. To provide an overall account of the structural formation of the economy of Bangladesh.

b. To present the picture of three broad sectors contribution towards the GDP of the economy over time.

c. To explore and ascertain the reasons behind the transformation.

d. Asses the probable implication on the economy itself.

\section{GROWTH PERFORMANCE OF BANGLADESH ECONOMY}

If we focus on one of the vital elements of macroeconomic analysis, that is regarded as an important indicator of measuring the performance of an economy i.e., growth rate of GDP as well as per capita GDP, it will be observed 
that growth performance of the Bangladesh economy has been mixed. As can be seen from Figure 1, since the 1970s through early 1980s there has been volatility in the growth rate of GDP. During 1976-1980, the economy achieved an average growth rate of about 4.3 percent. During 1981-1990, the growth rate was stalled at below 4 per cent. Over the past three decades, the growth rate has been noticeable, particularly since 2000 .

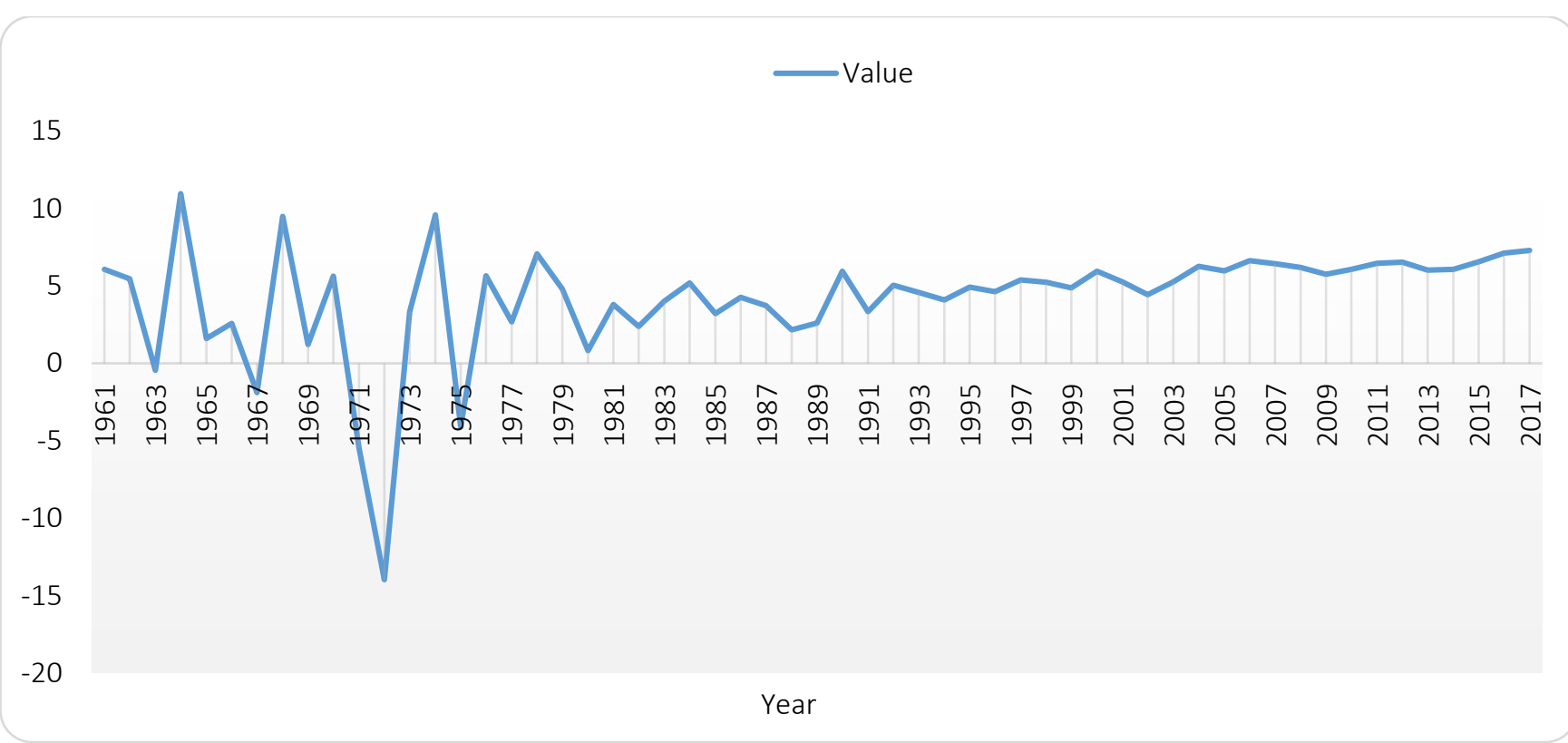

Figure 1. Trends in the Growth Rate of GDP.

Growth performance of Bangladesh economy can be summed up as follows:

- The decade, immediately after independence, the economy experienced a GDP growth more or less below 4 percent and since the late 1980s, it has started moving upward.

- In the 1990s, the economy grew at an average rate of 5 percent.

- During the period 2001-11 the economy grew at an average rate of just less than 6 percent.

- During the period 2005-11 the economy registered an average rate of 6.5 percent.

- After then it started growing upward.

Thus, it can be said that the growth of the Bangladesh economy showed variable trends up to the early 1990s. Since then, it has trended upward. Traditionally; agriculture has been the mainstay of the Bangladesh economy in terms of contribution to GDP. Agriculture maintained a steady linear real growth rate of 2.54 percent during the $1980 \mathrm{~s}, 3.22$ percent during the $1990 \mathrm{~s}$, and 3.53 percent during 2000s. The sector registered a growth rate of 5.24 percent in 2010 and between 201116 it registered a rate of 3.56 percent.

Bangladesh inherited a low industrial base at the time of independence. The flourishing of the readymade garments (RMG) sector since the mid-1980s has been pivotal to the growth of this sector. The average growth rate of this sector increased to an impressive 9.08 per cent during the 2000s from 6.96 percent during the 1990s. The growth performance of manufacturing sector, according to the latest survey, was higher at 21.74 percent in 2015-2016 against 21.01 percent in the previous year.

The services sector comprises the bulk of the GDP. The mean growth rate of services sector was 4.48 percent during the 1990s and to 7.10 percent during 2000s and 6.23 percent during 2010.The growth rate of the service sector rose to 6.71 percent in fiscal 2015-2016 from 5.80 percent in previous fiscal year and its share in the GDP stood at a slightly lower level by 0.19 percentage points to 53.39 percent in the year $2015-2016$ from 53.58 per cent in the previous year. 
Table 1. Annual Growth Rates of the Three Broad Sectors at Constant Prices (Selected Years).

\begin{tabular}{|c|c|c|c|c|c|c|c|c|c|c|c|c|c|c|}
\hline Sector & $\begin{array}{l}\vec{\infty} \\
\stackrel{\sigma}{\sim}\end{array}$ & $\begin{array}{l}0 \\
\stackrel{2}{\sigma} \\
\stackrel{\sigma}{\sim}\end{array}$ & $\stackrel{\sigma}{\sigma}$ & $\begin{array}{l}\circ \\
\text { Һ̆ } \\
\sim\end{array}$ & 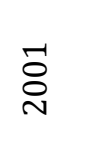 & $\stackrel{\circ}{\stackrel{0}{0}}$ & 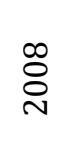 & $\begin{array}{l}\text { Oे } \\
\text { Oे }\end{array}$ & $\stackrel{0}{\stackrel{0}{0}}$ & $\overrightarrow{\vec{\sigma}}$ & $\begin{array}{l}m \\
\stackrel{n}{1} \\
\stackrel{\sim}{*} \\
\stackrel{\sim}{N}\end{array}$ & $\begin{array}{l}\stackrel{+}{\vec{n}} \\
\stackrel{\sim}{\vec{N}}\end{array}$ & 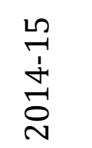 & $\begin{array}{l}0 \\
\stackrel{1}{1} \\
\stackrel{1}{n} \\
\stackrel{-}{N}\end{array}$ \\
\hline Agriculture & 3.31 & 3.31 & 2.23 & 3.10 & 3.14 & 2.21 & 3.20 & 4.63 & 5.24 & 4.96 & 2.46 & 4.37 & 3.33 & 2.67 \\
\hline Industry & 5.13 & 6.72 & 4.57 & 6.98 & 7.45 & 8.28 & 6.78 & 5.43 & 6.49 & 8.16 & 9.64 & 8.16 & 9.67 & 11.21 \\
\hline Service & 3.55 & 4.10 & 3.28 & 3.96 & 5.53 & 6.40 & 6.49 & 6.25 & 6.47 & 6.63 & 5.51 & 5.62 & 5.80 & 6.71 \\
\hline
\end{tabular}

Source: Bangladesh Bureau of Statistics (BBS) (Prepared by the author).

A careful study of Table 1 suggests the following:

- Growth in agriculture sector depicts a decreasing trend during 1981 to 1995 , but the sector grew almost at an average rate of 5\% during 1996 to 2000 , fell to 2.5 percent average growth during 2001 to 2006 . Thereafter it showed an increasing trend. Over the period 2010 to 2016, the agricultural sector grew at an average rate of 3.84 percent.

- The industrial sector showed steady upward growth throughout the sample period, except for slight drifts in the early 1990s and 2009. Between 2010 and 2016, the industrial sector has grown at an average rate of 8.89 percent.

- The services sector grew at a slightly higher rate (3.5 to 4.0 percent) than the agricultural sector. The services sector started flourishing since 2000. Between 2010 and 2016, the services sector has grown at an average rate of 6.12 percent. Since the early nineties growth in the services sector depicts an increasing trend.

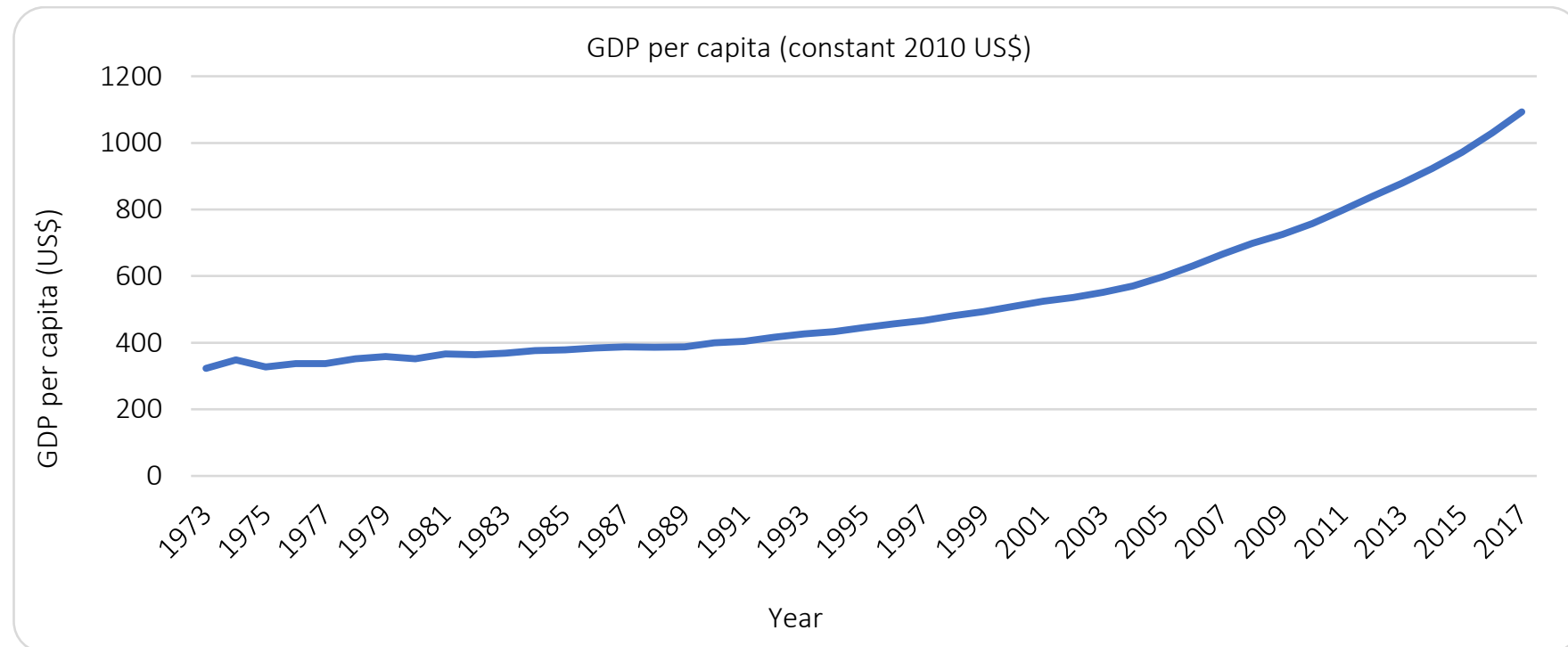

Figure 2. GDP per capita of Bangladesh (US \$) (GDP per capita of Bangladesh has followed an increasing trend over time).

OVERALL CHANGE IN THE COMPOSITION OF OUTPUT The variable growth performances of the three broad sectors have resulted in evident changes in the Bangladesh economy. The trend in the structure of Bangladesh GDP is presented in Figure 3 that depicts, over time, the relative contribution of agriculture to GDP has diminished considerably. In 1972-73 agriculture contributed just less than 40 per cent to GDP that came down to 15.97 in 2015-16. The relative contribution of the industrial sector to output steadily rose over time, except for slight drifts in the 1970s. Its share to GDP was 15.55 per cent in 1972-73 that showed slight variability up to 1980 . The industrial sector showed steady growth since 1980 and its relative share to GDP reached. In 201516 , the relative contribution of the services sector has steadily increased. This sector contributed about $46 \%$ to 
GDP in the early 1970s. Since 1978, the share of the services sector has been hovering around 50 per cent. Thus, the services sector remains the largest sub-sector of the Bangladesh economy. The key findings include:

- The share of the agriculture sector to GDP was almost halved between 1973 and 2017

- The share of industry doubled during the period mentioned above.

- The role of the services sector has been further elevated.

- As a sequel to the above, there has been a huge shift from the agricultural sector to the industrial sector as well as a moderate shift in favour of the services sector.

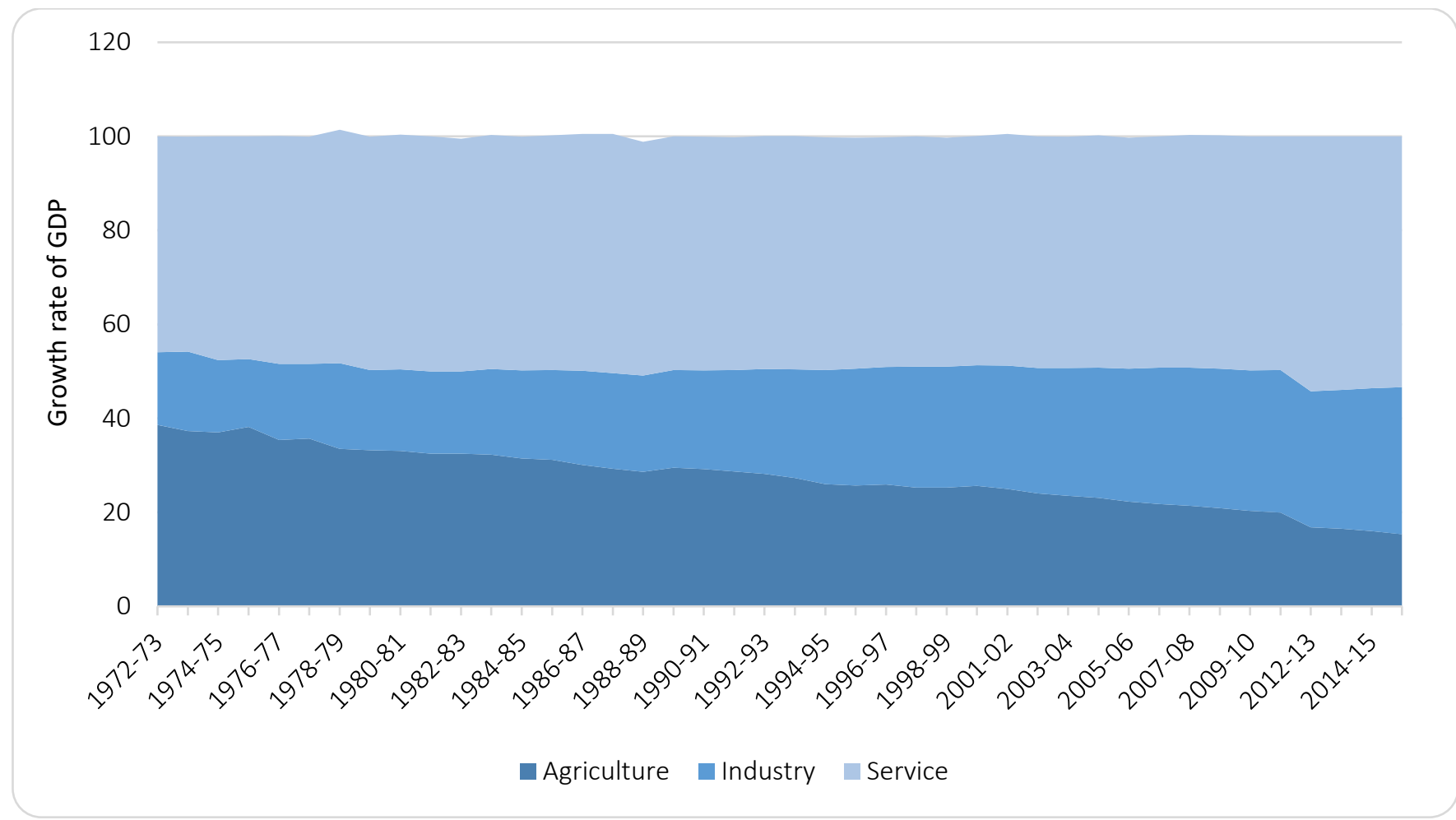

Figure 3. Trends in the Structure of GDP.

In addition to the overall transformation in the share of GDP, the relative contribution to the incremental value added is also an important indicator of the sectoral performance and their underlying dynamics. Table 2 presents the share of the absolute contribution of each sector to the incremental GDP. During the 1980s, the services sector contributed nearly 50 percent to the incremental GDP, while the contribution of the industrial sector was 29 percent and that of agriculture was 21percent. Over the years, the share of agriculture to incremental value added consistently declined. By 2013 14 , it fell to 9.84 percent whilst the shares of industry and elevated to 38.20 and 51.16 percent respectively. Therefore, an analysis of the contribution of diverse sectors to the incremental GDP growth in the last few years revealed that industrial sector spearheaded by manufacturing sub-sector made the lead contribution in this context as well, meanwhile growth rate of service sector surpassed growth rate of the industrial sector.

Table 2. Contribution of Different Sectors to Incremental GDP (Percent).

\begin{tabular}{ccccccc}
\hline Sector & $1980-90$ & $1990-2000$ & $2001-06$ & $2013-14$ & FY 15 & FY16 \\
\hline Agriculture & 21.1 & 18.8 & 11.0 & 9.84 & 0.53 & 0.43 \\
Industry & 29.2 & 34.2 & 36.1 & 38.20 & 2.74 & 3.24 \\
Services & 49.7 & 47.0 & 52.9 & 51.16 & 3.00 & 3.21 \\
\hline
\end{tabular}

BBS 2000, 2014, 2016. 


\section{STRUCTURAL FORMATION OF DIVERSE SECTORS} The Structure of Agricultural Output: The relative contribution of the agricultural sector although has been waning with time, Bangladesh economy still depends heavily on the mentioned one. In terms of absolute contribution to GDP, the sector is still growing, thereby having a great influence on major macroeconomic objectives like employment generation, poverty alleviation, and capital accumulation, reducing income inequality, human resources development and assuring food security as well. The agriculture sector can be subdivided into the crop and non-crop sub-sectors. Historically, the crop-sector dominated the agricultural sector to its output, owing to the huge demand for food by a large and expansive population. Rice, jute, sugarcane, potato, pulses, wheat, tea and tobacco are the principal crops. The non-crop sub-sectors include fisheries, livestock and forestry. The fisheries and livestock sector plays a vital role in the economy because as a labour-intensive and quick-yielding sector they augment economic growth through creating income-generating employment and therefore alleviate poverty. A recent survey revealed that around 1.3 million people are directly employed in the fisheries sector alone. The fisheries sector includes open water bodies such as rivers, canals, lakes, etc. and closed water bodies such as ponds and flood-control polders total 4 million hectares. Almost $80 \%$ of the country's protein requirement, around $70 \%$ of exports in the primary commodity category and almost $9 \%$ of total export come from this sub-sector. The four sub-sectors, namely, (a) Crops and vegetables, (b) livestock, (c) forestry, and (d) fisheries together contributed about 14.73 percent to GDP and more than 62 percent to the services sectors output in 2016-17. The relative shares of all the subsectors has experienced a declining trend over time except the fisheries sub-sector, which showed a gradually increasing trend till 2000-01 and thereafter a declining trend.

Figure 4 and 5 show that the agricultural sector has undergone perceptible structural changes in terms of $t$ relative contributions of the crop and non-crop products as well as the within the crop and non-crop categories. Crops and vegetables contributed over 46 percent to GDP, on the average, during 1973-76. The share of the crops and vegetables sub-sector declined sharply over the years. By mid-1980s, its share fell to just over 33 percent.
In 2010, crops and vegetables contributed only 11.34 percent to GDP. The growth rates of this sector have been variable over the years including negative growth in 1995.

With an annual growth rate of over 3 percent since 1993, the contributions of the livestock sub-sector to GDP and the agriculture sector as a whole stood at 1.66 percent and 1.60 percent respectively in 2015-2016 and 2016-17 respectively. The sector shows plentiful potential to develop itself as a commercial sector having ample employment as well as income generating opportunities both in the rural and urban areas. A significant number of private enterprises-cattle, poultry and dairy farms have been playing a catalytic role in the flourishment of the sector in recent years.

Due to high population pressure, the total forest area of the country has declined over time. By 1980 about 16 percent of the land was forested, and presently the amount is 12.5 percent. The sector contributed 9 percent to agricultural output in 2016, which was 1.66 percent of GDP. The relative contribution of fishery has been more or less steady over time. Its average share to GDP during 1973-76 was 4.70 percent, which stands at 6.23 percent in 2016-2017. The growth rate of this sector has been steady, quite impressive in recent years when compared with the overall growth pattern of the agricultural sector.

The major trends in the agricultural sector can be summarized as follows:

- As a sub-sector, crops and vegetables has declined over time in terms of its contribution to GDP. The sector also underwent a volatile pattern in its growth rate.

- Livestock and forestry depict a moderate increasing trend over the years in terms of growth, while their relative shares in GDP do not show perceptible changes, although some variability is apparent.

- The fishery sub-sector although experiences variable growth rates, its relative contribution to GDP remains steady over time, the growth rate of this sector depicts a volatile trend as well.

- Since crops and vegetables comprise the bulk of the agricultural output, it is the inconsistency in the growth rate of this sector that is responsible for the declining share of agriculture to the GDP of Bangladesh. 

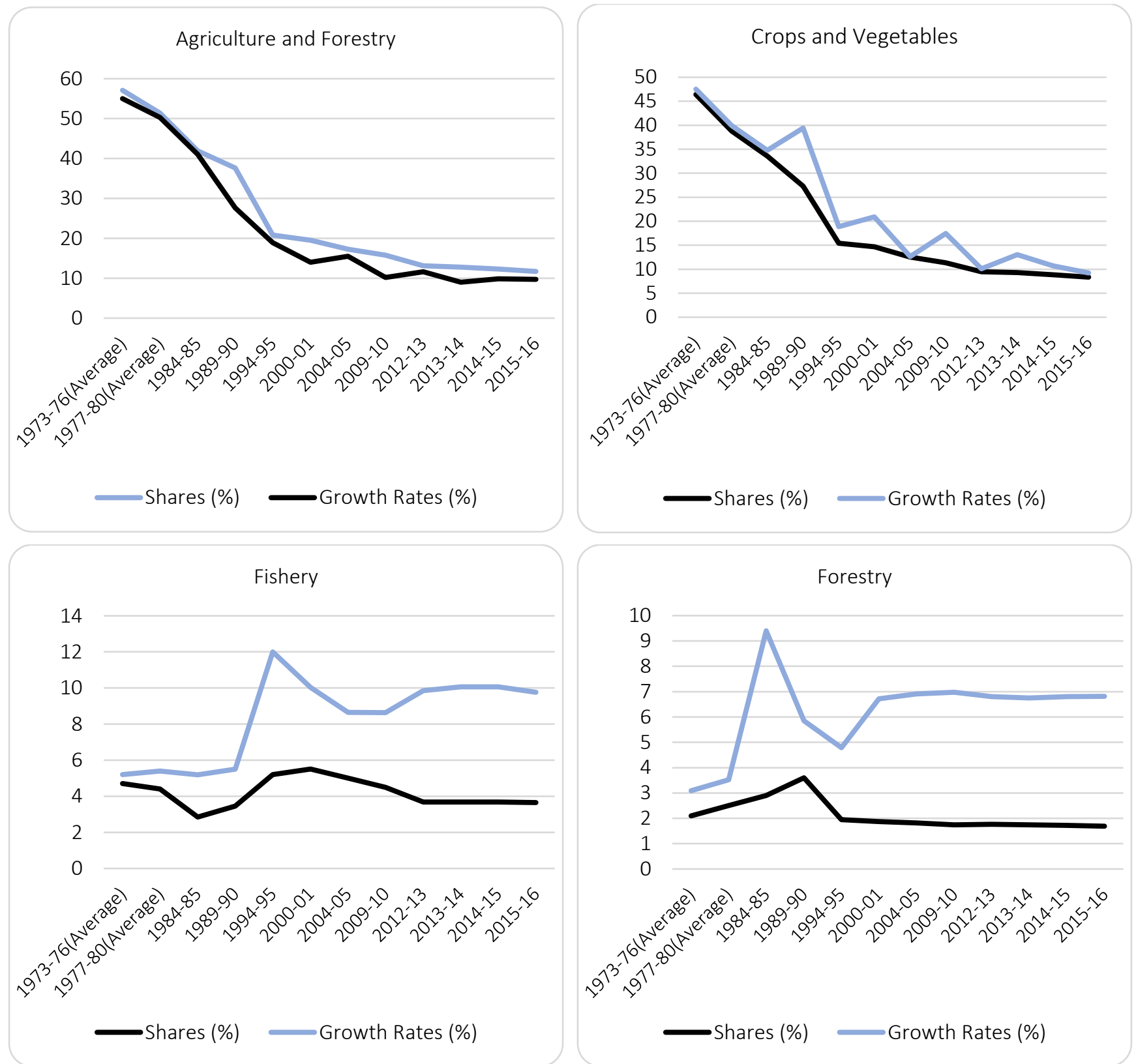

Figures 4. Growth rate and Share of different sub-sectors of the Agriculture sector.

The Structure of Industrial Output: Rapid industrialization is a prerequisite for sustained development as well as the achievement of social progress in a developing country like ours. In order to accelerate pro-poor economic growth, a general consensus is that Bangladesh has to ensure radical structural shift favouring the industrial sector. Industrial development in Bangladesh, during the postindependence period, both in terms of its growth rate and as well as structural change, has been rather modest. Therefore successive Industrial policies followed by a number of contemporary policies have been adopted, to revamp the sector with a view to creating sustainable and inclusive industrial growth through generation of productive employment to create new entrepreneurs, mainstreaming the women in the industrialization process and also creating international market linkage and to avail that goals, emphasis has been laid on infrastructural development, diversification of the economic base, accelerated economic growth, employment generation, raising income level and as well as development of the livelihood of mass people. 

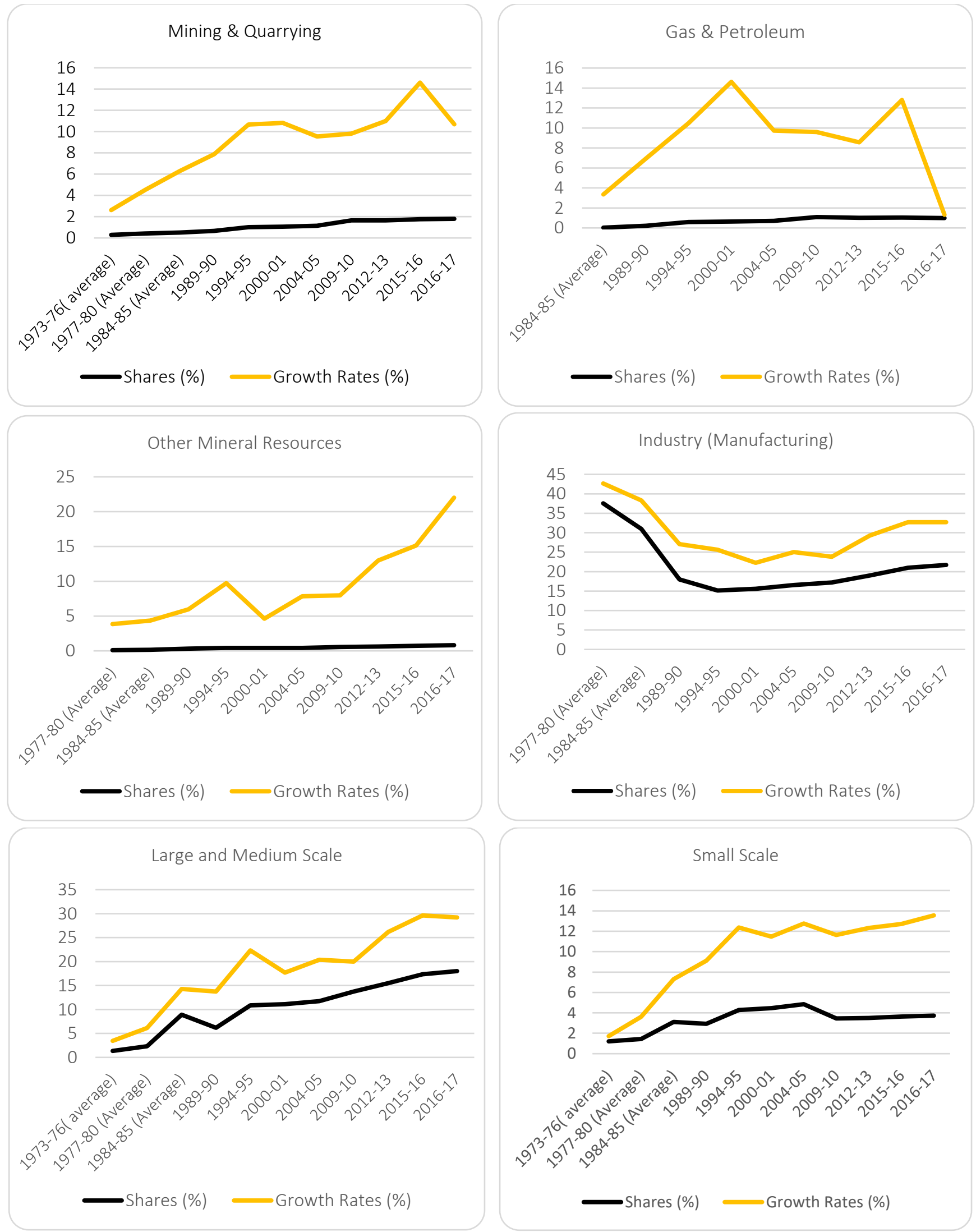

Figures 5. Growth Rate and share to GDP of different Sub-Sectors of Industrial Sector (Part A). 


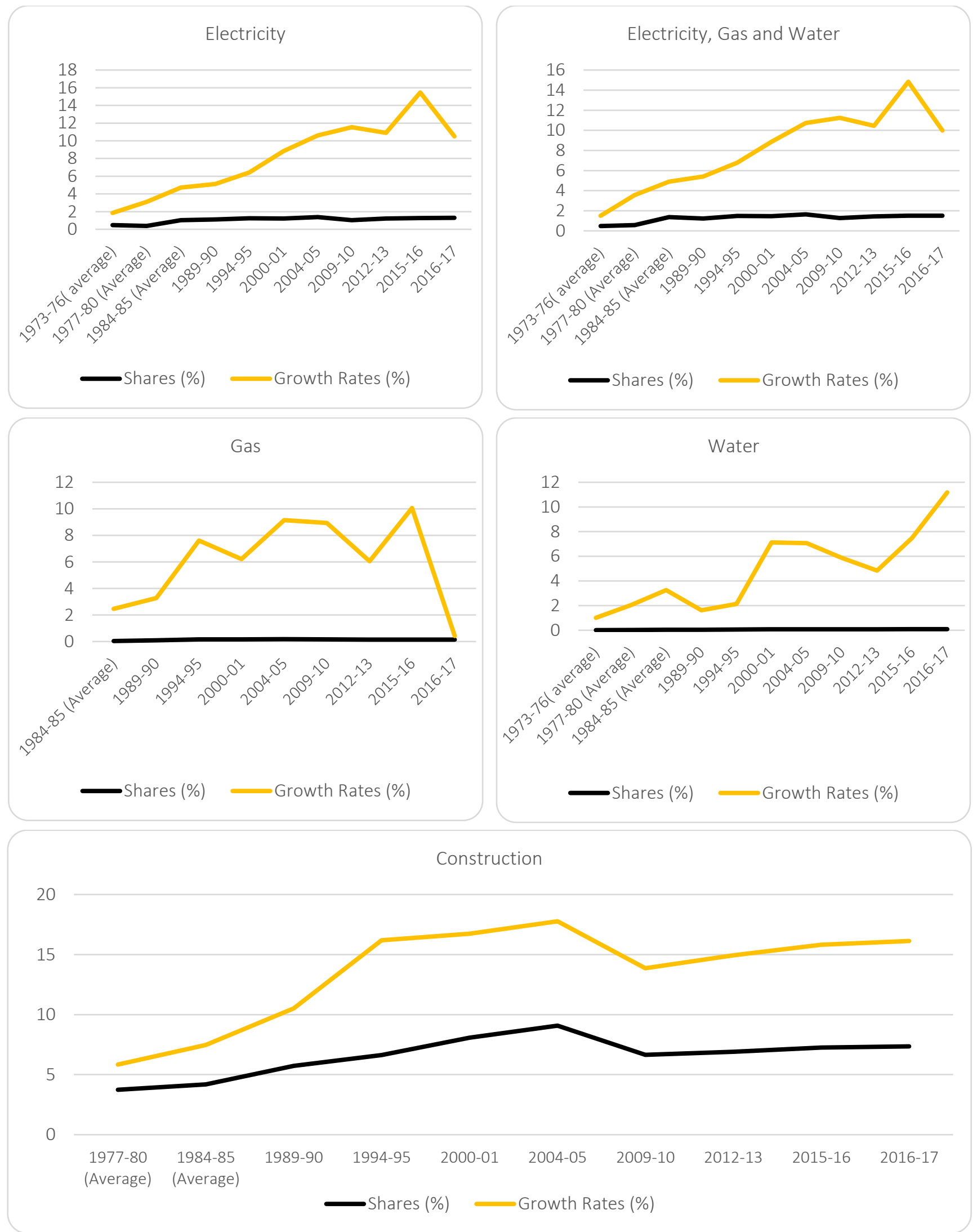

Figures 5. Growth Rate and share to GDP of different Sub-Sectors of Industrial Sector (Part B). 
Industry sector comprises of four sub-sectors namely, 1) Mining and quarrying 2) Industry (Manufacturing) 3) Electricity, gas and water and 4) Construction.

As can be seen from above, Manufacturing is the leading sub-sector of the industry that contributes most to GDP. This sector contributed over 47.55 percent to GDP, on the average during 1977-1980. Over time, the share of this sector observed a moderate increase as its contribution to GDP has however increased at a slower rate of late and calculated at 21.01 percent and 21,74 percent in FY 20152016 and FY 2016-2017 respectively. Accordingly, rate of growth has observed an increasing trend over time except for a moderate drift during 1998-1999 and 2009-2010.

The growth of this sub-sector has been benefitted from a better performance by both small scale and large and medium scale enterprises. The growth rate in the large and medium manufacturing sector has observed a continually rising trend in-between 1973-1995, whereas except in FY 1998-1999 (growth rate fell to about 4.19 percent) it continued the same as well.

Additionally, since 1973-76 to 2004-05, small scale industries experienced a rising share to GDP of Bangladesh, whereas, after that period the relative share followed a declining trend. Moreover, except a significant drift during FY 1998-99 (0.75 percent) the growth rate of this sector observed a moderately volatile trend over the mentioned period (1973-2017).

Manufacturing exports, especially of readymade garments (RMGs), have played a crucial and catalytic role in the flourishing performance of this sub-sector. RMG exports increased from an insignificant amount in the early 80 s to $\$ 2.5$ billion (6 percent of GDP) in FY 1996 and \$28.14 billion in FY 2017.

The contribution of electricity, gas and water supply to GDP is insignificant, although the respective sub-sector is considered to significantly facilitate the process as well as the pace of industrialization. Over the examined period the overall contribution of this sector to the GDP of Bangladesh followed a consistent trend as well. However, from FY197305 this sector observed an increasing growth trend and after that period the trend becomes slightly volatile.

Construction as an emerging sub-sector of industry has been booming since the mid-1990s fueled by strong manufacturing sector growth and a large amount of remittance inflow coming primarily from the Gulf countries. Between 2000-17 construction sector contributed around 7.38 percent to GDP on an average as well.
Moreover, following the highest increase of 4.77 percentage points between FY 1989-99 and FY 1994-95 the rate of growth of this sub-sector stood at 8.56 percent and 8.77 percent in FY 2015-16, FY 2016-17 respectively. The relative contribution of mining and quarrying has been more or less steady over time.

If we look at the growth pattern of this sub-sector it will be noticed that since 1973-76 to 1994-95 the mentioned sub-sector has followed a rising trend. Particularly, during the period of 1998-99, the sector experienced a perceptible downturn in its growth rate, later it followed a steady rate having slight volatility over time.

The major trends in the industrial sector can be summarized as follows:

- As a sub-sector, mining and quarrying has followed a snail's pace of rising trend over time in terms of its contribution to GDP. The sector also underwent a slight volatile pattern in its growth rate.

- Manufacturing sector depicts a moderate increasing trend over the years, in terms of growth, while their relative shares to GDP also keep pace with the growth pattern as well.

- The Electricity, Gas and Water sub-sector although experiences uprising growth rates except for a few exceptions, whereas its relative contribution to GDP remained quite steady over time.

- Since construction comprises a significant portion of the industrial output, its relative contribution, as well as growth, has followed more or less a consistent pattern.

\section{THE COMPOSITION OF SERVICES SECTOR}

As presented in Section 5, the services sector has played an increasingly important role in the economic growth of Bangladesh over time. The services sector also displayed greater dynamism vis-à-vis industry and agriculture. Over the past three decades, the Bangladesh economy has become more market-oriented. One key feature of the policy reforms undertaken in Bangladesh during the 1980s and the early 1990s was the liberalization of the service sectors, especially the telecommunications, community social and personal services and the financial sectors. As agriculture and industry sector, the services sector also underwent structural changes to an extent in terms of relative shares of the various sub-sectors within the services sector and their respective growth rates. Figure 6 in two parts depict the relative shares along with the growth rates, of these sub-sectors for selected years. 

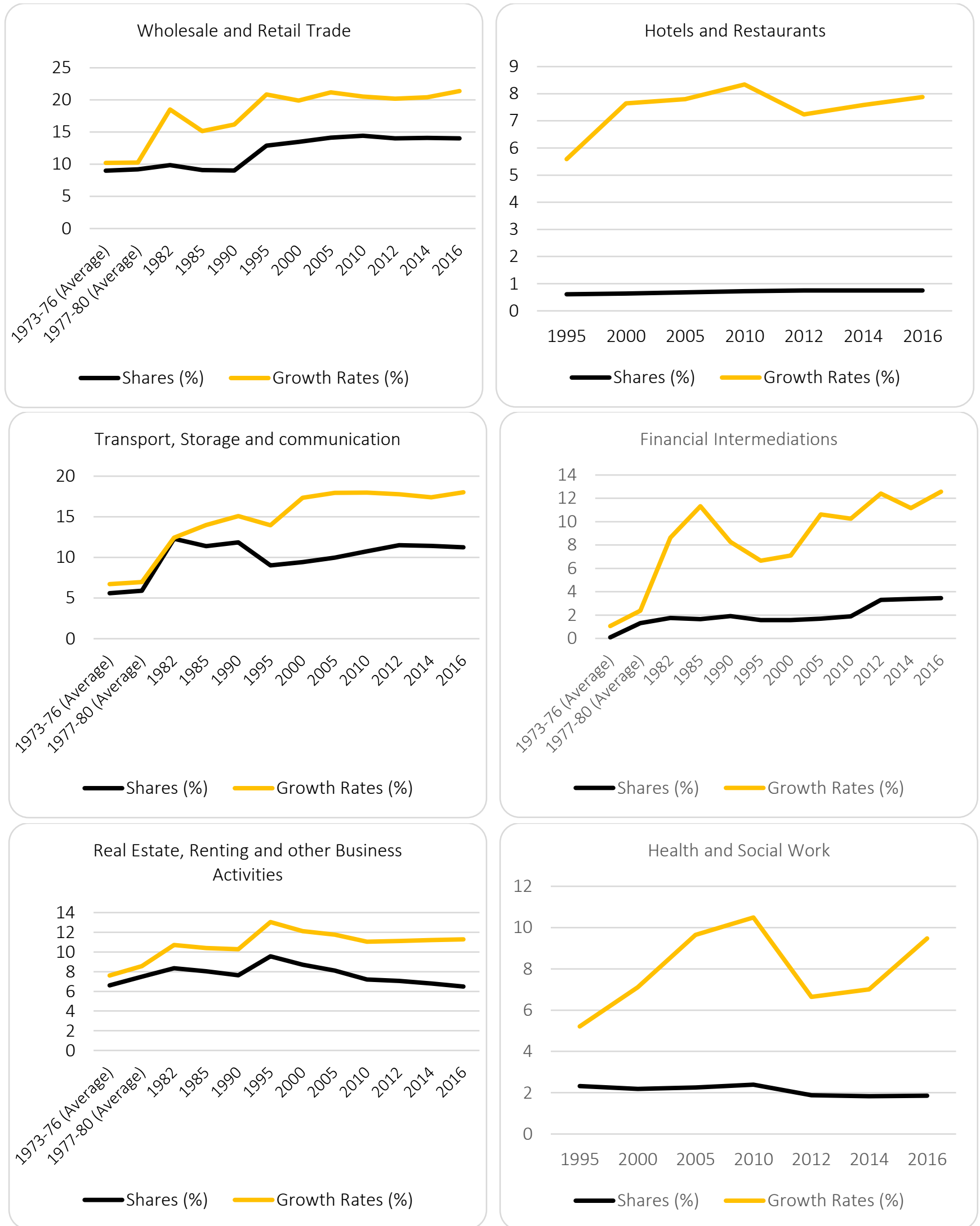

Figure 6. Growth rate and share to GDP of Different sub-sectors of Service Sector (Part A). 


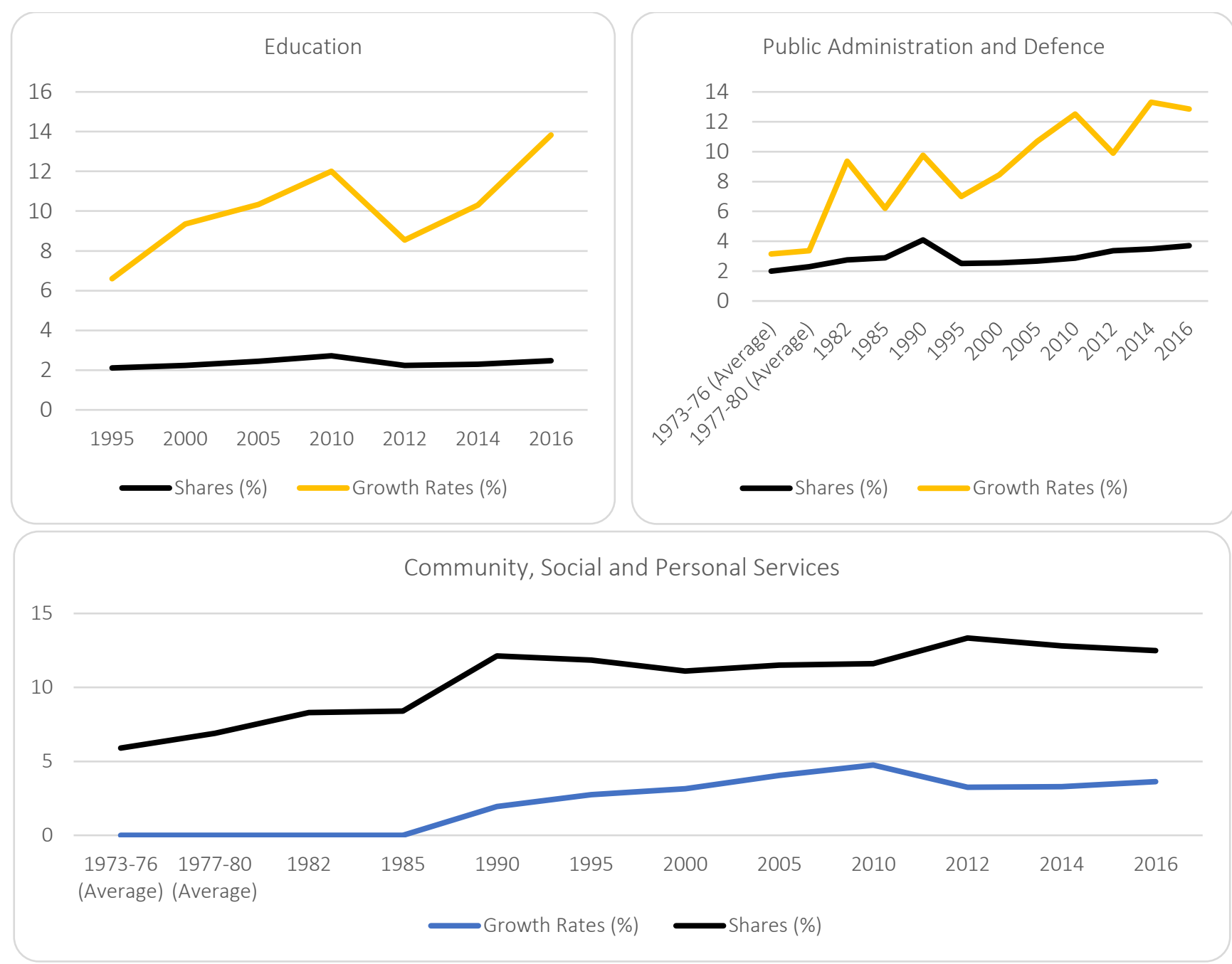

Figure 6. Growth rate and share to GDP of Different sub-sectors of Service Sector (Part B).

The services sector is dominated by four sub-sectors, namely; (a) wholesale and retail trade, (b) transport, storage, and communications, (c) real estate and renting, and (d) community, social, and public services. These four sub-sectors together contributed about 43.76 percent to GDP and more than 76 percent to the services sectors output in 2016-17. While the relative shares of wholesale and retail trade, and transport, storage, and communications have steadily increased over time, real estate and renting, and community, social and public services suffered declining trends, as can be seen from the sectoral shares trends for these sub-sectors. Contrarily if we concentrate on the growth trends of the different subsectors it will be observed that hotel and restaurant, financial intermediations, public administration and defence, education, health and social work sub-sectors experienced a faster growth trend compared to the rest.
The transport and communications sector experienced high growth that is mainly attributed by the strong growth posted by communications that comprise telecommunication, IT and postal services as well. The underlying causes of the robust growth in this sector are liberalization and as well as reforms in these sectors. For example, deregulation policy for the telecommunication sector, and market-driven reforms, as well as foreign private investment in this sector, has created a huge demand for new products which have been instrumental in attracting new foreign investment in this sub-sector. The flourishing of the private transport system also played a pivotal role.

The declining trends in the relative shares of the four subsectors (that is, (a) wholesale and retail trade, (b) transport, storage, and communications, (c) real estate and renting, and (d) community, social, and public 
services) combined with the rising share of the services sector as a whole suggests that at least some of the other sub-sectors outperformed the dominant sub-sectors in terms of growth rates.

\section{ANALYSIS AND FINDINGS}

The above discussion brings one of the notable issues, of sectoral pattern of economic growth as well as development, that occurred in Bangladesh economy, is, from the historical experience to present day evidence, it is quite evident that in course of the overall development process the country has undergone a particular pattern of structural change itself, viz., diminishing share of agriculture in GDP associated with, first, increasing share of industries followed by a rising share of services.

Whereas, structural transformation is defined as the reallocation of economic activity across the three broad sectors that encompasses agriculture, manufacturing, which accompanies the process of economic growth. It is said that economic activity between sectors can shift over time and the shifting can also happen within sectors and across sub-sectors within the same broad economic sectors as well. Moreover, in both cases, the process of change is generally reflected as structural transformation or structural change. McMillan and Rodrik has empirically shown that the transfer of labour and inputs to higher productivity activities is a driver of economic development as Arthur Lewis originally hypothesized.

One of the earliest and most central insights of the literature on economic development is that development entails structural change. The countries that manage to pull out of poverty and get richer are those that are able to diversify away from agriculture and other traditional products. As the labor and other resources move from agriculture into modern economic activities, overall productivity rises, and income expand. The speed with which this structural transformation takes place is the key factor that differentiates successful countries from unsuccessful ones.

Various work on this subject attempted to establish some stylized facts, that is the patterns of development followed by most countries and among them, the most well-known are Fisher (1939), Clark (1940), Kuznets (1966) and Chenery and Syrquin (1975). They postulated that as the economy grows, production shifts from the primary (agriculture, forestry, fishing, mining) to the secondary (manufacturing and construction) to the tertiary sector services. It is also notable is Rostow (1960), who argued that an economy passes through the various stages of development from the traditional stage to the take-off stage to the mass consumption stage. Our present literature is mostly descriptive, tried to provide a far-reaching overview of the development process of the economy concerned with the emphasis on exploring the underlying causes and its multifaceted implications as well.

Agriculture: As discussed earlier, the share of agriculture has declined from about almost 40 percent of total GDP during the 1970s to just about 16 per cent in 2016-17. Several factors contributed to the declining share of the agricultural sector in total output. First, the amount of arable land has been shrinking by almost one per cent per year due to increasing demand for housing and fragmentation of land as the population grows, building infrastructure and industries as well as loss of land from river erosion. It is revealed from a recent study, that the completely unprotected floodplains of the Ganges, Brahmaputra, Padma and Meghna are inhibited by 4.3 million people, of whom 2.2 million live on char land. Erosion resulted in the displacement of over 728,000 people during 1981-94. Second, Rivers of Bangladesh deposit an estimated average of 2 billion tons of sediments every year, that have raised the river beds, thereby lowering their water conveyance capacity which gradually renders those lands uncultivable. Third, Location of Bangladesh is in a paradoxical situation where patterns of rainfall are quite erratic that causes of too much or too little water during different seasons of the year. In a normal year, about 30 percent cultivable area is inundated. That results in a colossal amount of agricultural output. Non-availability of surface water during the dry season makes agriculture dependent on groundwater resources. Fourth, an analysis of districtlevel data on yield trends shows that despite the rising trend of input levels, yields have been declining or stagnant on about two-thirds of the area using highyielding variety (HYV) rice during the past decade and stagnant throughout the country. Intensive rice cultivation may also result in declining yields. Although noteworthy public support, as well as private initiative to raise productivity, has been pursued, stagnant or declining yields indicate that land quality degradation is particularly liable for reduced productivity. Multiple cropping may make the situation even more critical. Fifth, commercial logging, fuelwood extraction, shrimp culture, contraction of agricultural land and infrastructural development have led to continuous depletion of forest 
resources over the past few decades. Sixth, due to the intrusion of saline water in the south-western region of the country as well as water-logging due to lack of proper drainage and unplanned infrastructural development, siltation of rivers, and faulty designs of flood control structures may also have caused the agricultural output to decline.

The declining share of agricultural output to GDP has farreaching consequences for the Bangladesh economy. As mentioned earlier, agriculture still employs just less than half the civilian labour force. The declining share of agriculture coupled with agricultural mechanization has the connotation that employment in agriculture will continue to fall. With population rising, the manufacturing and the services sectors have to absorb an increased number of people if unemployment has to be reduced. The rural to urban migration might rise over time. Due to the declining importance of agriculture in the economy, investment for the long-term development of land is steadily diminishing. Moreover, in the context of growing population as fragmentation of land has been increasing so as to amount of landless people also, hence their standard of living is waning. The rural-urban income inequality will further deteriorate, and it may also cause rural to urban migration whose impact is both diverse and deep as at both ends there exists economic as well as socio-cultural impacts that that might be positive as well as negative. Amongst them, the positive benefits include higher production and better income from economic perspective vis-a-vis lowering of the age at marriage, reduction of fertility rate. The declining share agriculture has implications on the environment also. Air and water pollution may further increase. Encroachment of productive agricultural land and forest, the growth of slums, and the pressure on urban services may further intensify the environmental problems.

Industry: The decline in the share of agriculture accelerated during the 1990s that coincided with the intensified phase of policy reform. During this and the subsequent decade, the decline in agriculture's share was matched by an increase in the share of industry, with the share of the services sector remaining virtually unchanged. Manufacturing has all along been the dominant component of the industrial sector and its share in GDP increased from about $10.5 \%$ in the early eighties to 20.77 percent in 2016-17. A similar picture is seen with regard to employment share, with manufacturing having a more dominant position because of higher labour intensity in manufacturing compared to the other components of the industrial sector.

It is noteworthy that, in the case of the industrial sector it is the large and medium Industry that has been playing a catalytic role in the flourishment of the overall sector as well. In continuation of the above, it is observed, large Industries combined share in the performance of the industrial sector as a whole, has increased from 52 percent to 71.8 percent according to the recent estimate. However, the incremental share as well as the contribution of the industry sector doesn't necessarily imply that, performance of all sectors are up to the mark, in fact, it is quite evident that industrial base is continuing to be more narrow as a large number of these industries are experiencing negative growth, and it is worth mentioning that the reason liable to this retarded performance varies from industry to industry as well. Jute and textile industries that was considered as the most vital role-playing industries of our economy has experienced waning demand, shortage of raw materials, a synthetic substitute, corruption as well as lack of proper monitoring of the administration. Both paper and sugar industry have suffered from the displacement of the competing imports as well as lack of government patronage and high production cost.

Besides these, tea, fabricated metal products, nonmetallic mineral products, pharmaceuticals, iron and steel, transport equipment all these factors are also experiencing the negative as well as the stagnant growth. Contrarily, performance of certain Industries as readymade garments, leather tanning and products, plastic products, sulfuric acid, Chemicals, paper, caustic soda, ceramic, glass, Steel, cement, fertilizer, still and Engineering, pottery and Chinaware, Frozen Food etc. registered robust growth due to the availability of raw materials, domestic as well as for in demand, large scale private sector investment.

Since, the 1980s to early 1990s, as the dominance of the public sector was waning, the government adopted New Industrial Policy 1982, following a series of adjustment as well as a change in the state policy. Under these, 1076 state-owned enterprises were handed over to the private owners but unfortunately the initiative doesn't work well as they started losing their competitiveness and turn out to the losing concerned due to the and healthy less experienced ownership among whom many of them were more inclined of getting cash credit by selling the cheaply acquired property rather than 
supporting or developing them.

Moreover, the share of public investment has come down from 57 percent in 1980-81 to 4.67 percent in 2009-10 and later moved to a slightly upward at 7.41 percent in 2016-17.

Total manufacturing investment remained less than 5 percent of GDP throughout the last two decades, FDI in EPZs accounted for less than 15 percent of the total manufacturing investment during the period of the fifth five year plan and the major portion of this FDI flow goes for garments, textile, footwear and other labor-intensive industries that accounted for about 65 percent of total investment as well.

Realizing the fact as well, successive industrial policies has been adopted by the successive government, to revamp the industrial sector by focusing on private sector-led industrial growth, putting more emphasis on the market-based competitive economy. In addition to this, with a clear sense of direction of having a sizable industrial sector where manufacturing should account for at 30-35 percent of GDP and 30 percent of the employed workforce, more focus on SMEs as well as reducing poverty and hunger to less than half by 2017 , through the adoption of short, medium and long run program that may assist to build a modern, more vibrant industrial sector that will lead country to achieve its desired goal to attain the target of uplifting it's status to a developing nation, by achieving the prime macroeconomic objectives like reducing poverty, hunger, inequality of income, enhancing employment opportunity as well. Moreover, government continues to implement the privatization program as well as rehabilitation of identified industries that includes: One glass Factory, One cement factory, one paper mill, one newsprint mill, 8 oil mills, two fish processing unit, 6 cigarette factories ,two food processing unit, two cold storage, one beverage producing unit, three chemical industry,12 pharmaceutical industries

Industries that are marked due to their notable performances since 1990 include: automobile assembling, telephone equipment, electrical goods, TV assembling, cigarettes, shipbuilding, oil refinery, insulator and sanitary wares, vegetable oil (Revo-refined edible vegetable oil).

Our present study reveals that performance of small, medium industries are in most of the cases surpassed the performance of large scale industries and the factors that are considered liable to these uneven performance includes- less organized market, as well as the constraint that originates from limited size of the domestic markets, poor and less organized infrastructure, law and order situation, absence of skilled as well as semi-skilled labors, inadequate technical expertise, underdeveloped legal system, red-tapism and weakness of Institutions.

However, it can be said that, in order to accelerate the pace of industrialization that is optimum for Bangladesh, different policy issues as, monetary policy ,fiscal policy, infrastructure, currency movement ,interest rate spread, loan, structural issues, saving-investment gap, states role in industrialization, product and market diversification, under implementation of ADP as well as over expenditure of non-development allocated budget, these visible structural bottlenecks, that are considered liable for relatively underperformed industrial sector, needs to be addressed properly.

The increasing importance of the industrial sector has some positive as well as negative implications on the economy. On the positive side, apart from increased output and contribution to GDP the industrial sector created ample employment opportunities as well as a good number of technicians, entrepreneurs, and investors to meet the growing demands from diverse sectors, invited enhanced foreign investment, and diversified the economic base. The negative implications include, among other things, overall environmental degradation aroused from water, soil air, and sound pollution, and unplanned urbanization.

Services Sector: During the course of the overall trade policy reform in Bangladesh, the liberalization of the services sector (especially telecom and financial sectors) received much importance. Service sectors are increasingly becoming the core of Bangladesh economy. In the context of South Asia where growth rates in the services sector has been fluctuating during the last two and a half decade, India and Bangladesh have been the exceptions with consistent growth. The overall growth performance of services sector indicates that, taking the advantages of liberalization policy pursued by successive governments regarding greater participation of private sector in trading business, banking and insurance business, telecommunication sector, education sector has played an important role in thriving of overall services sector as well as industry sector, agriculture sector, communication sector, housing sector etc. Furthermore, cost efficiency, profitability, competitive behaviour and higher services among the various industry participants has also intensified. The growth of the services sector is 
viewed as a post-industrialization phenomenon. As incomes continue to rise, people's needs become less "material" and they begin to demand more services - in health, education, entertainment, and many other areas. Meanwhile, labour productivity in services does not grow as fast as it does in agriculture and industry because most service jobs cannot be filled by machines. This makes services more expensive relative to agricultural and industrial goods, further increasing the share of services in GDP. The lower mechanization of services also explains why employment in the service sector continues to grow while employment in agriculture and industry declines because of technological progress that increases labour productivity and eliminates jobs. Eventually, the services sector replaces the industrial sector as the leading sector of the economy.

One merit of the services sector growth is that it requires relatively less natural capital and more human capital than producing agricultural or industrial commodities. In a resource-scarce economy like Bangladesh, the services sector can be an effortless way out to employ the vast human capital. Another benefit of the growing service sector is that by using fewer natural resources than agriculture or industry, it puts less pressure on the local, regional, and global environment as well. Conserving natural capital and building up human capital may help country development become more environmentally and socially sustainable.

\section{CONCLUSION}

This paper is an attempt to analyzing the changes that have occurred to the sectoral composition of Bangladesh's GDP over the period of 1973-2017. The changing trends in three broad sectors of the economy, namely, agriculture, industry and services are scrutinized in terms of their growth patterns and relative contribution to GDP. Each of these three broad sectors is further analyzed to examine the structural changes occurring within the sectors itself. The paper then proceeds to identify the underlying causes behind the structural changes that resulted and also underlines the plausible implications associated with the structural transformations. As a prelude to the structural transformations, the paper outlines the growth performance of the Bangladesh economy.

\section{REFERENCES}

Abdullah. A. and Q. Sahabuddin. (1993). Critical Issues in Bangladesh Agriculture: policy response and unfinished agenda. Ministry of Planning, Dhaka.
Ahmed, Nazneen, Mohammad Yunus and Harunur Rashid Bhuiyan. (2008). Promoting

Employment -Intensive Growth in Bangladesh: Policy Analysis of the Manufacturing and

Service Sectors. Unpublished Paper, ILO, Geneva.

Bakht. Zaid. (1995, January). Preparation of Fifth Five Year Plan: Position paper on Industry.

Bah, El-hadi Josef C. Brada. (2009). Total Factor Productivity Growth, Structural Change and Convergence in Transition Economies, Comparative Economic Studies, 51,421-446.

Bangladesh (2012, April 02). The World Factbook CIA Online. Retrived from http://www.foodsecurityatlas.org/bgd/country/f ood-security-at-a-glance.

Centre for policy Dialogue (CPD). (1995). Experiences with Economic Reform: A review of Bangladesh's Development.

Chenery, H.B., and M. Syrquin. (1975). Patterns of Development, 1957-1970. London: Oxford University Press.

Centre for policy Dialogue (CPD). (2001). Policy brief. Industry and Trade.

M.B. Diego, Bangladesh: Economy Overview and Structural Changes.

Fisher, A.G.B. (1939) Primary Secondary and Tertiary Production, Economic Record, 24-38.

Haq. S.A. Rahman, and G. concoay. (1990). Environmental aspects in agricultural development in Bangladesh. Dhaka. University Press Limited.

H. Berthold, R. Richard., V. Akos. (2013). Growth and Structural Transformation.

Imam, M.H. (1994). Bangladesh environment: a political ecology of degradation, IBS Journal, 17.

Imam, M. H. (1994). Perspective plan for cro agriculture development; Ministry of Agriculture, 1995-2010.

Johnston BruceF. And Jhon W. Mellor, (1961). The Role of Agriculture in Economic Development, American Economic Review, 51,566-593.

Jhonston, Bruce F and Peter Kilby. (1975), Agriculture and structural Transformation: Economic Strategies in Late Developing Countries, Oxford University Press,

Laitner, J. (2000) Structural Change and Economic Growth. RE Stud.

Lewis, J. (1954). Economic Development With Unlimited Supplies of Labor. Manchester School.

Lewis, J. (2006a): The Nexus of economic growth 
employment and poverty reduction: An empirical analysis, in Islam.

Lewis, J. (2008): Has Development and Employment Through Labor-Intensive Industrialization Become History?

M.K. Mujeri. (2004). Changes in policy framework and factor productivity in Bangladesh. Vol.XXX.

Ministry of Environment and Forests. (1991). National Conservation Strategy of Bangladesh towards sustainable development, Dhaka.

Ministry of Environment and Forests. (1992). Environment policy.
Ministry of Planning. (1995). The Fourth- Five Year Plan, 1990-1995. Dhaka, Planning Commission.

Ministry of Agriculture (1995) Perspective plan for crop agriculture development; 1995-2010. Dhaka, Policy Planning Branch.

Naher, K. (2006). An analysis of the growth trend and changing the structure of GDP of Bangladesh.

Report on the Task Forces on Bangladesh Development Strategies for the 1990s, Developing the infrastructure, VOL. III; UPL; 1993

The Fifth Five Year Plan, 1997-2002; Planning Commission; Ministry of Planning; GoB. 